\title{
European projects on district energy-renovations and Italian best practices
}

\author{
Lorenzo Teso ${ }^{l,}$, , Tiziano Dalla Mora ${ }^{2}$, Piercarlo Romagnoni ${ }^{2}$, and Fabio Peron ${ }^{2}$ \\ ${ }^{1}$ Free University of Bozen-Bolzano, Faculty of Science and Technology, Piazza dell'Università 5, Bolzano, Italy \\ 2 IUAV University of Venice, Department of Design and Planning in Complex Environments, S. Croce 191, Venezia, Italy
}

\begin{abstract}
Buildings are the major source of greenhouse gas releases: lowering their energy consumption and emissions is particularly challenging for the existing building stock. This topic was examined at an individual building level in the International Energy Agency's EBC Annex 56. However, the increasing request of nearly zero energy buildings highlight another important topic: the need of an increase in energy production for satisfying the required amount of renewable energy sources. This task could be solved at the district level for the existing buildings, even if it is a complex issue. This work presents a general introduction on the topic of Urban and Regional Integrated Energy Planning, with a focus on the regional and supraregional process to create and manage energy plans. After the first introductory part, the method is explained through a description of its main phases and the tools used. The subsequent section presents a general overview on the European projects that deal with the problem of district regeneration; the ones that are more related to the topic of this work are considered in a deeper way through tangible applications in Italian cities. The study of already done examples will help in the definition of benefits and drawbacks, with the aim to defining newer and better energy planning procedures.
\end{abstract}

Keywords: Energy planning; building retrofit; district heating and cooling; methods and tools; decisionmaking process.

\section{Introduction}

Urbanization theories from the late 50's point out that national priorities and typical characteristics of the region need to be taken into account in order to proceed toward a sustainable urban development. In this framework, after the 1970's oil crisis, the International Energy Agency (IEA), with the support of several Countries, proposed a new approach to deal with the use of energies in communities: the Integrated Energy Planning (IEP), a tool developed to support the longterm planning processes of expansion areas.

Only from the 90's ecological and environmental concerns started to shift the attention of the planning approaches to the effects of the human activities on the environment [1]. These considerations led to the developing of a new way of urban planning: Urban and Regional Integrated Energy Planning (UR-IEP). This approach major characteristic is a strong bond between international, national and local government institutions that co-operate to involve in the planning process multiple stakeholders and different sectors and interests under a comprehensive understanding of the urban sustainable energy policies [2].

\section{Urban and Regional Integrated Energy Plans}

"UR-IEP mechanism takes into account various available resources and demands in a region. This implies that the assessment of the demand, the supply and their influence in the energy system, must be at a similar geographic scale. Regional energy planning exercises need to be flexible (to cope with rapidly changing energy systems) and easy to use" [3]. The URIEP method helps decision makers in the definition of strategies, therefore UR-IEP requires appropriate approaches and procedure to be helpful; however, there is not a comprehensive framework to support this tool in the decision-making processes, leading to neglect important factors in the planning strategies.

From a methodological point of view, considering all the previous energy-planning plans, a common scheme emerges; the planning processes can be divided in 4 phases [4]:

- Phase 1: preparation and orientation

- Phase 2: model design and detailed analysis

- Phase 3: prioritization and decision

- Phase 4: implementation and monitoring

\footnotetext{
* Corresponding author: lorenzo.teso@natec.unibz.it
} 


\subsection{Methods and tools}

The section presents the different phases that characterize the development of an integrated planning and it provides for every phase a brief description of the actions carried out during its implementation.

\subsubsection{Phase 1: preparation and orientation}

The first phase in the definition of the UR-IEP, as in all other planning instrument, is the preparatory phase: in this step all the preliminary actions required to produce an energy plan are included. The aim of this phase is the creation of a supportive database of information necessary to proceed in the energy plan workflow, the identification of major restrictions and criticalities to define a common planning strategy involving all the interested actors, such as experts and decision makers. The data collected in this phase represent the description of the building stock analyzed from geometrical, socio economic and energy utilization aspects $[5,6]$. The use of geographic information systems (GIS) can optimize the data collection process: these instruments permit to store, manage and visualize large amounts of data expressing them in a simple and intuitive way, helping the involved stakeholder in visualize and comprehend the urban energy situation of the building stock, and reshape it following sustainable objectives in a better way [1].

The most used software for the first phase of planning works are GIS-based tools, since the major works of the first phase consist in collecting data to recreate the reality in a virtual ambient. This support tools help also in store a large amount of data, manage, pre-process and visualize them in a simple way.

An example is the internet portal [7] launched by the European Commission (EC) to propose shared goals for future green development and help local governments dealing with setting targets for sustainable growth.

\subsubsection{Phase 2: model design and detailed analysis}

A great number of methodologies have been developed over the years in order to assess the energy consumption of stocks of buildings, all with the integration of GIS. All the existing methodologies can be divided into two classes. Top-Down approach consists in the determination of building performances starting from aggregated data and finding a relationship between statistical info on the features of the construction and the related consumptions. Bottom-up approach foresees the definition of the overall performances of the stock starting from the evaluation on the single building level, information are deduced through official statistics, energy performance certificates or by means of a numerical model. In the past studies, the top-down approach was use to assess large-scale analysis, but it is not suitable for improvements at building scale. Instead, bottom-up approach is more suitable for regional and urban analysis since modelling energy systems requires a detail-based approach [8].
Energy models created with a bottom-up approach can be divided into Building Physics Model and Statistical Model [9-11].

BUILDING PHYSICS MODELS: these models can be considered very traditional since they rely all their calculations on traditional thermophysical relations. Following the division proposed by Swan and Ugursal [11] there are three categories:

-Archetype method: it is the most used model in the recent past and it consists on the aggregation of buildings in groups by means of key characteristics $[12,13]$.

-Sample method: the use of data collected with surveys and monitoring campaigns on the actual buildings are necessary to simulate their behavior [14].

-Population distribution method: it is a modelling method that depicts consumption scenarios starting from the energy consumption of household appliances and the ownership saturation rate of appliances $[15,16]$.

STATISTICAL MODELS: these methods rely on the search for correlation between buildings characteristics, external conditions and historical data on energy use in the studied buildings. They can be divided into two major categories:

-Regression analyses method: they try to find the relation between the energy consumptions of a building and the drivers that cause them. To achieve reliable results the calculations need to be done with a huge amount of inputs [17, 18];

- Neural network (NN) method: is mostly used to evaluate the energy consumption and the impact of social and economic factors on a single building level, however it is not very suitable for defining energy saving measures [19-21].

There are different types of tools, developed by different organizations and groups that can be used in this phase of the work, but the characteristics of those tools are similar to one another. The goal of these programmes is to assess long time allocation of investments among various alternatives measures that consider all the economic sectors and track environmental impact of every choice in both demand and supply side to find the best combination of technical solution that can fulfill the needs of a community. To do so it is possible to simulate a period of one year with hourly time-steps, or longer periods of $20-50$, up to 100 years combining annual simulation's results into longer time series.

\subsubsection{Phase 3: prioritization and decision}

Traditionally, the energy planner considers as unique objective the cost benefit maximization. However just this single criterion cannot describe the multidimensional and conflicting concepts typical of a developing region, since that is a continuously evolving dynamic organism. For these reasons, appropriate tools and methods need to 
be used while working on topics such as energy regional planning. The two more widely used approach to this topic are Multi-Criteria Decision Analysis (MCDA) and Multi-Criteria Spatial Decision Support System (MCSDSS). They both are support tools for evaluation about sustainability and work in three steps: formulation of the problems by studying the current situation; design the planning models by different intervention solutions; and decision of the most suitable between the various alternatives [22]. The difference is that in the MC-SDSS the necessity of data visualization and georeferencing required the use of GIS in the model.

The tools used in this phase of the work are mostly collaborative programmes or web-based platforms in which decision makers can express their preferences regarding the plan to adopt taking into consideration criteria for projects' evaluation and alternatives to them, receiving feedbacks that can help the decision makers in their choice for the right results.

\subsubsection{Phase 4: implementation and monitoring}

In this phase of the work, the main aspects of the energy plans are usually decided. What the main actors try to do is to implement the plan's steps by adding projects or programmes in order to improve the results the plans can reach. This phase is used also in the case the results are not satisfactory for the involved actors: plans are analyzed to find flaws and shortcomings and support projects can be developed to correct them. Moreover, the simple monitoring of the realized projects is carried out in this phase to prove the merits of the plans and to suggest them as examples for other realities [4].

The last phase of the work consists mainly in monitoring the already decided energy plan. The programs used in this part are mostly communicative and quality management tools used to monitor and observe how the plans work [4].

\section{European Union's Framework Programmes}

Climate changes derived from greenhouse gas (GHG) emissions have a strong bond with energy use and consumption derived from buildings and infrastructures. In the last decades, policy makers from all over the world started to undertake a serious fight, at all government levels, against the climate changes' trigger factors [23].

Since the Earth Summit held in Rio de Janeiro in 1992, the European Union (EU) always assumed a role of leadership in both international and European climate change and energy governance, launching ambitious programmes to slow down the inevitable changes that planet Earth is suffering [24]. In order to maintain the effort, and to make sure that every Member State (MS) was on board with EU projects, a series of funding programmes was created with the specific intent to promote the studies on climate changes and their triggering factors and try to propose and evaluate solutions to the problems of the GHG emissions and energy use [25].

The Framework Programmes for research and Technological Development are a series of founding programmes created by the EU to foster and support researches in various scientific fields. The first program named Framework Programme 1 (FP1) was established in 1984 and, as for the following programmes until the sixth, lasted 5 years with an investment of 3.8 billion Euros. In 1994 the EU launched the FP4, this was the first program launched after the 1992 Rio conference and it was the first where investment capital passed the 10 billion Euros, doubling the founding from the previous Framework Programme (from 6.6 to 13.2). The mentioned increase in the available capitals for research shows the intention of the EU to become a leader in the study on climate changes since the beginning [24].

\subsection{Seventh framework programme}

The seventh Framework programme (FP7) for Research and Technological development was the funding program that the EU started in 2007 and ended 7 years later in 2013. The program had a budget of 50.5 billion Euros, an increase compared to the previous programs' budget that shows the high interest that EU has regarding research, development and innovation. The economic support from the EU is focused in determined research fields, defined as priority areas to make or keep Europe a world leader in those fields.

FP7 consists of 4 main blocks of activity corresponding to the main research areas in which the EU aims to invest capitals; in particular, $64 \%$ of the total funding, corresponding to over 32 billion Euros, is reserved for projects concerning cooperation across the EU and beyond its borders. This very activity block contains economic support intended to foster researches and projects on the very delicate topics of energy and environment [26, 27].

In those particular fields of research, it is possible to find important projects that aim to develop strategies for design, constructing and managing key renovation works to tackle the energy use and GHG emissions.

In Europe $40 \%$ of the energy consumption and about $36 \%$ of the total carbon dioxide $\left(\mathrm{CO}_{2}\right)$ emissions are caused by the current building stock, formed by about 160 million buildings. Since the construction of new buildings only represents the $1.5 \%$ of the actual building stock, and this trend is expected to continue as it is in the next years. The focus needs to be put on renovation of existing buildings and districts and demonstrate the replicability of those processes to achieve substantial impact in terms of energy saving and GHG reduction. In the funding schemes of FP7 three major projects are recognize as a boost in renovation of building at a larger level than the singular residential unit: EU-GUGLE, R2CITIES and SINFONIA [28]. 


\subsubsection{EU-GUGLE}

EU-GUGLE stands for "European cities serving as Green Urban Gate towards Leadership in sustainable Energy" and it is founded under the FP7 for Research and Technological Innovation.

The EU-GUGLE project aims to demonstrate the feasibility of nearly-zero energy buildings and district renovation models in order to activate large-scale replication processes in cities and communities by the year 2020. During the 5 years project, eight pilot cities, namely Vienna (AT), Aachen (DE), Milan (IT), Sestao (ES), Tampere (FI) Bratislava (SK), Gothenburg (SE) and Gaziantep (TR), have committed to renovate more than $220,000 \mathrm{~m}^{2}$ of living spaces in order to achieve, by 2018 , primary energy saving between $40 \%$ and $80 \%$ per city and, in the same effort, increasing the renewable energy sources (RES) share by $25 \%$. Some other cities are expected to take part in the project during its lifetime, once the results have shown the feasibility of the expected outcomes.

To reach the proposed objectives the eight pilot cities joined their efforts to combine research and knowledge to achieve a smart renovation of group of buildings at a district level and to implement the outcome projects with a mix of financial, socio-economic and technical solution adapted to every local need. The renovation processes and outcomes were monitored and evaluated starting from a financial point of view, to the energy performances of the renovated buildings, to confirm the expected results.

The results of the strategies that the pilot cities developed during the 5 years projects are integrated in "smart renovation strategies", which can be easily replicated in other municipalities thanks to a Europeanwide replication campaign.

This project is part of the Smart Cities and Communities Initiative of the EC that aims to foster European-wide dissemination of good practices and best examples for helping cities and communities to achieve, by 2020 , a $40 \%$ GHG emissions reduction $[29,30]$.

\subsubsection{R2CITIES}

The aim of R2CITIES is the development and demonstration of replicable strategies for designing constructing and managing projects about large-scale district renovation in order to achieve nearly zero energy neighborhoods. The purpose of this project is to develop and demonstrate an easily replicable strategy through a demonstration and dissemination framework for innovative strategies and solutions for renovate of buildings at district level, towards a nearly zero energy district.

For the development of the projects, three different demonstration sites were chosen in different countries, climate conditions and with different users' habits, namely Genoa (IT), Valladolid (ES) and Kartal (TR). After determining the demo sites, the work continued with several studies and project ideas for the costeffective solutions for the improvement of the energy performances of the buildings at a district level. After completing the study part, since the first day of working, the demo sites were measured and verified thoroughly to define their energy performances and energy savings.

After the collection of data and good practices, an ambitious dissemination program was carried out to disseminate the results of the works and to ensure the diffusion and the replications of the pilot cities models. The three demo sites were used to demonstrate the goodness and replicability of the project's frameworks: the renovation plan of the districts involved almost $60,000 \mathrm{~m}^{2}$, more than 859 dwelling, and almost 2000 users for an estimated energy consumption reduction close to $60 \%[31,32]$.

\subsubsection{SINFONIA}

SINFONIA project is a 5 years initiative to organize large-scale energy solutions in European cities of medium size. Since almost $80 \%$ of European citizens live in urban areas, cities have a crucial role to play in the transition towards a low-carbon future. In reaching this objective, cities need to focus on at a higher level than the single building and try to develop integrated urban improvement strategies to make them more sustainable [33].

The two cities that represent the engine of this transformation are Bolzano (IT) and Innsbruck (AT), those realities started a collaboration that aims to achieve primary energy savings around 40 to $50 \%$ and an increase on the use of renewables around $20 \%$.

To reach the aforementioned objectives, the pilot cities developed an integrated set of measures to renovate more than $100,000 \mathrm{~m}^{2}$ of living surfaces and solutions to optimize electricity grids as well as improvement or construction of district heating and cooling systems.

After the designing and construction of the project's plans, the most difficult part was bridging the gap between the demonstration phase and the replication in other realities, even in larger scales. To make this phase easier, just a small set of district typologies with their relative retrofit interventions were defined, thus enabling the cluster of replication cities to easily access all the information needed to define their renovation strategies and, in this way, ensure the transferability and scalability of the projects. The cities that decide to participate in the project and adopt in the shortest period were Pafos (CY), Rosenheim (DE), Seville (ES), La Rochelle (FR), and Borås (SE) [34-36].

\section{Italian examples}

In all the presented projects, the main goal is the optimization of the heating systems of a city, meaning the refurbishment and improvement of energy infrastructures, built environments, urban design and services while ensuring the interaction between them. Important is also the involvement of stakeholders in the process: since the pilot cities are working on already existing districts, the implementations of planned measures would not be possible without the inputs from all the contributors [37]. 
Each pilot city has chosen a district with the intent of revitalize its life, functions, and set examples for the city itself and other realities in Europe. This is the main objective of the projects: "[to] provide replicable strategies and concrete solutions for large-scale refurbishment projects across Europe" [34].

In this context the concept of district needs a clarification. When the discussion is about city districts, we are talking about buildings one next to the other that form an agglomerate of services and housing solutions that create a variety of building use, capable of satisfy every need of the population hosted in the area. This type of area usually is easy to interconnect to a common energy supply system or it is already connected. The diversity on building use is reflected in a variety of stakeholders that influence decision-making processes and design phases.

Italy has an important role in the European scientific community about building and district renovation: since most of the building stock was built before the implementation of any European thermal regulation, constructions and energy distribution systems need refurbishments to achieve European standards [38]. Therefore, even in the abovementioned projects, it has a leading role, due the participation of Italian pilot cities in each program: Milan for EU-GUGLE, Genoa for R2CITIES and Bozen for SINFONIA.

In the following sections the important aspects of every projects related to Italian cities will be discussed.

\subsection{Milan}

Milan is the second largest city of Italy with a population of around 1.35 million people distributed in an approximate area of $182 \mathrm{~km}^{2}$. It is the main financial, industrial and commercial center of Italy and is divided in 9 administrative zones. "Zona 4" is one of the nine administrative areas of Milano and it is located at the southeast border of the city. With a population of about 152,000 inhabitants, spread on a surface of $21 \mathrm{~km}^{2}$, it has a density of about 7,250 inhabitants per $\mathrm{km}^{2}$, similar to the average density of every other district in Milan. "Zona 4" district thanks to EU-GUGLE project and its action and design implementation is a perfect case study for devising, testing and tuning innovative solutions to be replicable at the whole city scale [39].

The first intervention in the area was for a public residential complex, used as social housing, divided in two blocks of apartments: the gross floor area of the intervention was about $11,000 \mathrm{~m}^{2}$, with a total gross volume of $33,200 \mathrm{~m}^{3}$. The buildings lay in bad conditions and the occupants lived in a low-quality indoor environment because of envelope's low thermal performances and of a poor quality of the building systems. The works on the housing complex were divided in two main phases: the first one focused on the thermal insulation of the buildings, while the second phase concerned the improvement of the complex's technological systems.

In the first phase the envelope of the buildings was retrofitted by means of improving the thermal resistance of the external walls and floor by adding insulation layers on the existing structures, instead the roof was refurbished by flattening the pitched roof and adding insulation layers in the new roof's stratigraphy. The external glazing systems were replaced by new highperformance glazing and frame components, new external motorized solar protection devices were added. The intervention during the second phase was focused on the technological systems of the buildings: a decentralize mechanical ventilation system with heat recovery was installed and a passive cooling system was developed, using controlled natural night ventilation. Moreover, the management system of the buildings was updated by installing sensor for measurement of illuminance, $\mathrm{CO}_{2}$ and temperature and humidity, and dimmer and switches for illumination, ventilation system, external solar protector, windows opening and thermostat valve for the heating system. Finally, in order to reach the planned share of renewables in the project, a photovoltaic power plant was installed on the roof of the buildings and the heating system was connected to the local district heating network $[39,40]$.

The renovation works resulted in a reduction of $86 \%$ of the energy demand for heating and domestic hot water (DHW), passing from $250 \mathrm{kWh} / \mathrm{m}^{2} \mathrm{y}$ to $35 \mathrm{kWh} / \mathrm{m}^{2} \mathrm{y}$. This was possible thanks to the accurate refurbishment of the envelope, considering also the correction of the thermal bridges, which improved not only the energy performances of the building but also the thermal comfort of the indoor environment. To reach and overtake the initial goal of $82 \%$ in energy savings an important role was played by the connection to the district heating network and by the installation of photovoltaic panels.

However, some challenges and difficulties were encountered during the renovation processes because it was necessary to provide tenants with temporary accommodations during the works, since those needed to take place without the inhabitants. Working in an existing structure was also problematic for the fact that the structure was not flexible enough regarding the necessity to create spaces for the new technological equipment, and lastly the building construction company did not always demonstrate sensibility or attention in the installation of the insulation, causing problems and delays in the works [39].

Still the EU-GUGLE project is not done with Milan, the next moves will be the refurbishment of another two social housing buildings and the retrofit of a childcare center to reach a nearly zero energy building (nZEB) [40].

\subsection{Genoa}

One of the pilot cities of the R2CITIES project is Genoa, the administrative center of Liguria region and the sixth bigger city in Italy. With a population of almost 610,000 inhabitants is one of the largest city on the Mediterranean Sea and the largest seaport in Italy, hosting, since the $19^{\text {th }}$ century, massive shipyards and steelwork factories [41]. The demo site selected by the 
municipality of Genoa is located in the district of Pegli 3 , a zone in the western part of the city originally designated to host thousands of inhabitants. The area is divided into several zones with different end uses: undeveloped areas, social services, private housing complexes, public social housing and finally the part that represented R2CITIES demo site: the "Lavatrici" complex (washing machines in English because of the resemblance of the buildings to the electrical appliance). The Lavatrici complex was built between 1980 and 1990 in an area of $40,000 \mathrm{~m}^{2}$ and consist of 8 main blocks for a total volume of almost $230,000 \mathrm{~m}^{3}$, corresponding to $64,000 \mathrm{~m}^{2}$; due to the large size and the partly public and partly private character of the buildings, this housing district present several environmental and energy use criticalities. Efficiency is low in terms of transmittance and in terms of energy demand per square meter of total used floor area; the same can be stated for the hygrometric performances regarding interstitial and surface condensation and the formation of mold.

The buildings in the Lavatrici district present a cast reinforced concrete structure built on continue or pilotis foundation, a flat roof and vertical walls with different configurations: precast wall panels filled with thermal insulation on the external East-West walls; reinforced concrete wall with layer of hollow units and with thermal insulation South-North walls; windows are only in the East and West façades and are double glazed, filled with air and with a metal frame.

Since the district present a significant amount of built surfaces, the most suitable solution to achieve a nearly zero energy district was to consider in the projects only a part of the whole district: for the project, only the two high-rise blocks were considered, corresponding to almost 160 dwellings and $18,000 \mathrm{~m}^{2}$ of covered surface. The global energy demand of these blocks of dwellings were of $592,000 \mathrm{kWh} / \mathrm{y}$ and their energy consumption was $1,030,000 \mathrm{kWh} / \mathrm{y}$.

The intervention defined for the considered blocks of apartments was the replacement of the windows by new more performant ones, characterized by a heat transfer coefficient in the range between 4 and $2 \mathrm{~W} / \mathrm{m}^{2} \mathrm{~K}$ of the old windows to a U-value lower than $1.5 \mathrm{~W} / \mathrm{m}^{2} \mathrm{~K}$ for the new ones. This represents a medium cost intervention (around 1,000,000 $€$ for the windows substitution), but it contributes to reduce energy losses and heat gains. The energy saving given by this intervention was around $206,000 \mathrm{kWh} / \mathrm{y}$, leading to save $18,950 € / \mathrm{y}$ in energy bills and 41,200 kg of emitted $\mathrm{CO}_{2} / \mathrm{y}$.

The heating system was renovated as well: the old 628 $\mathrm{kW}$ natural gas fed boiler was changed with a more efficient $200 \mathrm{~kW}$ boiler and all the systems connected to it were renovated with innovative and more performant equipment. This intervention costed around 400,000 $€$ and saved $154,000 \mathrm{kWh} / \mathrm{y}$ of energy, reducing energy bills of about $14,200 € / \mathrm{y}$, and $\mathrm{CO}_{2}$ emissions were reduced by $30,900 \mathrm{~kg}$.

The last intervention was the installation of thermostatic valves and metering systems in all 160 considered dwellings. With a cost of $100,000 €$ this intervention saved $257,500 \mathrm{kWh} / \mathrm{y}$ of energy, $23,700 € / \mathrm{y}$ in the billing for energy and avoided $51,500 \mathrm{kgCO}_{2} / \mathrm{y}$.
In total, the whole interventions saved about $50 \%$ of the pre-intervention energy consumption, from a global energy consumption of $1,030,000$ to $510,000 \mathrm{kWh} / \mathrm{y}$; the global energy demand decreased to $474,000 \mathrm{kWh} / \mathrm{y}$ in comparison to the pre-intervention value of 592,000 $\mathrm{kWh} / \mathrm{y}(-20 \%)[42]$.

\subsection{Bolzano}

Bolzano is the Italian pilot city in the SINFONIA project. With its 108,000 inhabitants it is the capital city of the autonomous province of South Tyrol in norther Italy and it is a very active center for what concern retrofitting studies and green-energy development. In this optic, since 2005, the city developed a series of interventions' plans for the refurbishment of large portions of its urban pattern, planning to invest money coming both from private and public stakeholders [35].

The works of the SINFONIA project are part of this series of investments planning, with the project's works, to achieve a primary energy savings around $50 \%$ and increase the RES share of $20 \%$ in the demo sites [43].

The four demo sites in the city of Bolzano represent about 350 dwellings $\left(21,700 \mathrm{~m}^{2}\right)$ and just $85,000 \mathrm{~m}^{3}$, a small amount considering the numerous housing buildings in the city that still need a renovation to meet the ambitious standards set by the local and provincial administrators. They were all built between 1960 and 1985, and even if located in different part of the city, present the typical characteristics of the housing buildings of those years: they are composed of different adjacent blocks, each one of them served by a stairwell, connecting the various floors. The structure is a reinforced concrete frame with non-load-bearing exterior walls made of hollow bricks and an external polystyrene insulation layer with a variable thickness from 4 to $6 \mathrm{~cm}$. Old and not performant double glazed windows with wooden frame compose the glazing, on top of the windows the rolling-blind casing create a considerable thermal bridge. The technological systems are typical of the period as well: single-dwelling gas-fired boilers represent the heating and DHW generators with the notheated water supplied by means of poorly insulated piping passing in the empty spaces between the dwellings and the heating ensured by radiators.

The total consumption for DHW, heating and lighting of the buildings is about $880 \mathrm{kWh} / \mathrm{m}^{2} \mathrm{y}$, with an average consumption of almost $220 \mathrm{kWh} / \mathrm{m}^{2} \mathrm{y}$ per building.

The renovation measures designed for the considered buildings regarded mainly the external envelope of the blocks: to reduce at a minimum the impact and problems related to the building sites in all the demo area, prefabricated elements were used to renovate the buildings' façade. The main goals were the improvement of the thermal envelope of the structure by applications of thicker insulation layers and better performing glazing and framing systems, reduce the thermal bridges present in the business as usual (BAU) situation and improve the living quality by means of installation of a mechanical ventilation system. For what concerns heating and DHW the single unit boilers were removed, and the buildings 
were connected to the district heating grid, after the renovation of the piping lines. To help in the energy savings and to achieve the RES increase in all the demo sites photovoltaic panels were installed on the rooftop or on the south façade of the building, in case of unavailability of the roof, and solar thermal collectors were placed to cover up to $50 \%$ of DHW production.

The described interventions helped in savings about $75 \%$ of the energy consumption registered before the works, passing from 880 to $240 \mathrm{kWh} / \mathrm{m}^{2} \mathrm{y}$ (with an average of $60 \mathrm{kWh} / \mathrm{m}^{2} \mathrm{y}$ per building). This calculation does not take into consideration the contribution of RES thanks to which energy savings reach an average of $40 \mathrm{kWh} / \mathrm{m}^{2} \mathrm{y}$ per building $\left(160 \mathrm{kWh} / \mathrm{m}^{2} \mathrm{y}\right.$ in total) indicating that their impact is about $35 \%$ [44-47].

\section{Discussion and conclusions}

This study has drawn an overview on the most important aspects of the Urban and Regional Integrated Energy Planning. A summary of the most important methods and tools to define energy related projects points out how the process of designing and implementing an energy plan almost never takes into consideration all the parts of the process in a comprehensive way. Therefore, not all planning aspects, important for the success of the work, are taken into account in today used planning paths. This is shown, in part, also through the Italian examples described: European projects (e.g. the new project from IEA Annex 75 [48]) aim to develop projects that at the same time consider energy supply renovation and build retrofit and to apply them to large districts to reach even more important results in the fight against GHG emissions and energy use. Italian examples show how the projects are implemented in district composed of a small amount of buildings, even if the dwellings amount is high. Nonetheless, the results obtained by the work in this field is giving good results and the future developments seems promising.

From the considered examples, a series of common renovation strategies emerge as widely used in all the intervention works, thanks to their efficiency in reducing energy use (Table 1). These works can be considered as guidelines for future works on the building stock since their significant impact. Renovation interventions on the envelope of the building stock is a quite simple but very effective measure in reducing energy use and emissions; improving its thermal characteristics is one of the basic interventions in the building stock. This intervention can be designed with the use of external prefabricated façade systems that can take into consideration the substitution of old and outdated transparent elements and frames. Other important step in the renovation works is the attention paid in updating the heating and DHW systems in single buildings: is necessary to improve the characteristics of these systems with renovation works on pipelines and single generation and emission elements, but this is not enough.

In the future works, more attention needs to be paid in the renovation design of the whole energy supply network at a district level to couple it with the works on
Table 1 - Data summary of the analyzed case studies, with focus on the variation in energy demand and consumption in pre-intervention and post-intervention scenario, and the investment made for each case.

\begin{tabular}{llccc}
\hline Case study & & $\begin{array}{l}\text { Energy } \\
\text { demand } \\
{\left[\mathbf{k W h} / \mathbf{m}^{2} \mathbf{y}\right]}\end{array}$ & $\begin{array}{l}\text { Energy } \\
\text { consumption } \\
{\left[\mathbf{k W h} / \mathbf{m}^{2} \mathbf{y}\right]}\end{array}$ & [Million $\mathbf{~}]$ \\
\hline Milan & Pre-int. & 250 & $\mathrm{n} / \mathrm{a}$ & \\
& Post-int. & 35 & $\mathrm{n} / \mathrm{a}$ & 0.9 \\
\hline Genoa & Pre-int. & 33 & 58 & \\
& Post-int. & 27 & 29 & 1.5 \\
& & $-20 \%$ & $-50 \%$ & \\
\hline Bolzano & Pre-int. & $\mathrm{n} / \mathrm{a}$ & 880 & 14.7 \\
& Post-int. & $\mathrm{n} / \mathrm{a}$ & 240 & \\
& & & $-75 \%$ & \\
\hline
\end{tabular}

the single building to try to deal with RES to the energy demand of the building stock. Moreover, new studies and researches need to point in the direction of define the boundaries and shortcomings of these plans for bigger districts with an even higher number of dwellings and in more expanded areas and try to correct the mistakes found in the previous works' steps. Moreover, the challenge is to improve the strategy's quality in order to get more relevant and more accurate results in less time. For example, enlarge the sample of case studies in terms of typologies and quantities, going beyond the case studies that considers few single houses, so as to propose more innovative solutions of retrofitting according to the optimization of the energy grid design.

\section{References}

1. Torabi Moghadam, S., Delmastro, C., Corgnati, S.P., Lombardi, P.: Urban energy planning procedure for sustainable development in the built environment: A review of available spatial approaches. J. Clean. Prod. 165, 811 (2017).

2. Albeverio, S.: Book reviews. Syst. Sci. 87, 3 (2008).

3. Ramachandra, T. V.: RIEP: Regional integrated energy plan. Renew. Sustain. Energy Rev. 13, 285 (2009).

4. Mirakyan, A., De Guio, R.: Integrated energy planning in cities and territories: A review of methods and tools. Renew. Sustain. Energy Rev. 22, 289 (2013).

5. Caputo, P., Gaia, C., Zanotto, V.: A methodology for defining electricity demand in energy simulations referred to the italian context. Energies. 6, 6274 (2013).

6. Tornberg, J., Thuvander, L.: A GIS energy model for the building stock of Goteborg. 2005 Esri Int. User Conf. (2005).

7. European Sustainable Cities Platform | Home, http://www.sustainablecities.eu/.

8. Mendes, G., Ioakimidis, C., Ferrão, P.: On the planning and analysis of Integrated Community Energy Systems: A review and survey of available tools. Renew. Sustain. Energy Rev. 15, 4836 (2011).

9. Kavgic, M., Mavrogianni, A., Mumovic, D., Summerfield, A., Stevanovic, Z., Djurovic-Petrovic, M.: A review of bottom-up building stock models for energy consumption in the residential sector. Build. Environ. 45, 1683 (2010). 
10. Oladokun, M.G., Odesola, I.A.: Household energy consumption and carbon emissions for sustainable cities - A critical review of modelling approaches. Int. J. Sustain. Built Environ. 4, 231 (2015).

11. Swan, L.G., Ugursal, V.I.: Modeling of end-use energy consumption in the residential sector: A review of modeling techniques. Renew. Sustain. Energy Rev. 13 1819 (2009).

12. Corgnati, S.P., Fabrizio, E., Filippi, M., Monetti, V.: Reference buildings for cost optimal analysis: Method of definition and application. Appl. Energy. 102, 983 (2013).

13. Ballarini, I., Corgnati, S.P., Corrado, V: Use of reference buildings to assess the energy saving potentials of the residential building stock: The experience of TABULA project. Energy Policy. 68, 273 (2014).

14. Cheng, V., Steemers, K.: Modelling domestic energy consumption at district scale: A tool to support national and local energy policies. Environ. Model. Softw. 26, 1186 (2011).

15. Kadian, R., Dahiya, R.P., Garg, H.P.: Energy-related emissions and mitigation opportunities from the household sector in Delhi. Energy Policy. 35, 6195 (2007).

16. Saidur, R., Masjuki, H.H., Jamaluddin, M.Y.: An application of energy and exergy analysis in residential sector of Malaysia. Energy Policy. 35, 1050 (2007).

17. Fracastoro, G.V., Serraino, M.: A methodology for assessing the energy performance of large scale building stocks and possible applications. Energy Build. 43, 844 (2011).

18. Arambula Lara, R., Pernigotto, G., Cappelletti, F., Romagnoni, P., Gasparella, A.: Energy audit of schools by means of cluster analysis. Energy Build. 95, 160 (2015).

19. Nakata, T., Silva, D., Rodionov, M.: Application of energy system models for designing a low-carbon society. Prog. Energy Combust. Sci. 37, 462 (2011).

20. Connolly, D., Lund, H., Mathiesen, B. V., Leahy, M.: A review of computer tools for analysing the integration of renewable energy into various energy systems. Appl. Energy. 87, 1059 (2010).

21. Timmerman, J., Vandevelde, L., Van Eetvelde, G.: Towards low carbon business park energy systems: Classification of techno-economic energy models. Energy. 75, 68 (2014).

22. Wang, J.J., Jing, Y.Y., Zhang, C.F., Zhao, J.H.: Review on multi-criteria decision analysis aid in sustainable energy decision-making. Renew. Sustain. Energy Rev. 13, 2263 (2009).

23. Goldthau, A.: Energy Research \& Social Science Rethinking the governance of energy infrastructure: Scale, decentralization and polycentrism. Energy Res. Soc. Sci. 1, 134 (2014).

24. Oberthür, S., Kelly, C.R., Kelly, C.R.: EU Leadership in International Climate Policy: Achievements and Challenges EU Leadership in International Climate Policy: Achievements and Challenges. 2729, (2008).

25. Archives | CORDIS | European Commission, https://cordis.europa.eu/guidance/archive_en.html.

26. Home page - FP7 - Research - Europa, http://ec.europa.eu/research/fp7/index_en.cfm.

27. Pezzutto, S., Mosannenzadeh, F., Grilli, G., Sparber W.: European Union research and development funding on smart cities and their importance on climate and energy goals. Smart Sustain. Plan. Cities Reg. 2030, 421 (2017)
28. What is FP7? - FP7 in Brief - Research - EUROPA http://ec.europa.eu/research/fp7/understanding/fp7inb rief/what-is_en.html.

29. Resources, N.: Europe-wide replication of best renovation practices Sustainable renovation models for smarter cities Smart renovation for energy efficient cities. 1.

30. Project - EU-GUGLE, http://eu-gugle.eu/project/.

31. The Project, http://r2cities.eu/project/the_project.kl.

32. EuropeanUnion: R2CITIES - Project overview.

33. Ag, T.W., Rochelle, L.: Consorzio SINFONIA . Città che consumano meno e vivono meglio Innsbruck. 11.

34. Morishita, N., Heidenreich, M., Hemmers, R., Vankann, M., Sahakari, T., Vainio, T., Pagliano, L., Treberspurg, M., Österreicher, D.: EU-GUGLE: A Sustainable Renovation for Smarter Cities from a Pilot Project. In: Smart and Sustainable Planning for Cities and Regions. SSPCR 2015 (2017).

35. Sinfonia Smartcities - Project, http://www.sinfoniasmartcities.eu/en/project.

36. Nzengue, Y., Du Boishamon, A., Laffont-Eloire, K., Partenay, V., Abdelouadoud, Y., Zambelli, P., D'Alonzo, V., Vaccaro, R.: Planning city refurbishment: An exploratory study at district scale how to move towards positive energy districts - Approach of the SINFONIA project. 2017 Int. Conf. Eng. Technol. Innov. Eng. Technol. Innov. Manag. Beyond 2020 New Challenges, New Approaches, ICE/ITMC 2017 - Proc. 2018-Janua, 1394 (2018).

37. Pezzutto, S., Fazeli, R., De Felice, M.: Smart City Projects Implementation in Europe: Assessment of Barriers and Drivers. Int. J. Contemp. ENERGY. 2, 46 (2016).

38. Dalla Mora, T., Pinamonti, M., Teso, L., Boscato, G., Peron, F., Romagnoni, P.: Renovation of a school building: Energy retrofit and seismic upgrade in a school building in Motta Di Livenza. Sustain. 10, (2018).

39. Milano - EU-GUGLE, http://eu-gugle.eu/pilotcities/milano/.

40. Pagliano, L., Carlucci, S., Causone, F., Moazami, A. Cattarin, G.: Energy retrofit for a climate resilient child care centre. Energy Build. 127, 1117 (2016).

41. The Lavatrici District, Genoa, http://r2cities.eu/demos/genoa/case_study_in_short.kl.

42. M, D., Genoa, V.P.: R2CITIES " R enovation of R esidential urban spaces: Towards nearly zero energy CITIES ". 2014, (2014).

43. Sinfonia Smartcities - Bolzano, http://www.sinfoniasmartcities.eu/en/demo-city/bolzano.

44. SINFONIA Factsheet,Demonstration Building, Housing Complex - Via Palermo, (2017).

45. SINFONIA Factsheet,Demonstration Building, Housing Complex - Via Similaun, (2017).

46. SINFONIA Factsheet,Demonstration Building, Housing Complex - Via Passeggiata dei Castani, (2017).

47. SINFONIA Factsheet,Demonstration Building, Housing Complex - Via Brescia, (2017).

48. Almeida, M.: Cost-effective Building Renovation at District Level Combining Energy Efficiency \& Renewables. (2017). 